\title{
Life Cycle Management of Energy and Energy Transitions-Managing the Complexity of Todays and Future Energy Systems with a Life Cycle Focus: Challenges and Methodological Solutions
}

\author{
Karin Treyer, Roberto Turconi and Alicia Boyano
}

\begin{abstract}
To meet climate and sustainability goals a transition of the system of energy supply and use is needed. However, energy transitions are complex long-term processes and require a variety of methodologies to steer their direction. For this purpose, the combination of environmental, social, economic and technical assessments together with prospective energy scenario modelling is very promising but there are several challenges that need to be addressed to fully benefit from these methodologies. This paper presents the discussions held during a conference session on this issue. The solutions proposed facilitate the combination of energy system modelling frameworks and environmental and social assessments aimed at developing comprehensive prospective studies and feeding information to decision making processes for energy transition toward a low-carbon economy.
\end{abstract}

\section{Introduction}

In order to reach the pledges made under the Paris Agreement on climate change it is clear that an ambitious energy transition towards low-carbon solutions involving every part of the economy is needed [1]. Energy transitions, defined as structural changes in the way energy services are delivered and used, are inherently complex, uncertain and difficult to evaluate. In this context, it is increasingly acknowledged

\author{
K. Treyer $(\bowtie)$ \\ Paul Scherrer Institute, 5232 Villigen, Switzerland \\ e-mail: karin.treyer@psi.ch \\ R. Turconi \\ ArcelorMittal Global R\&D Sustainability, 57283 Maizières-lès-Metz, France
}

A. Boyano

Joint Research Center, Directorate B5 Circular Economy and Industrial

Leadership, 41003 Seville, Spain

(C) The Author(s) 2018

E. Benetto et al. (eds.), Designing Sustainable Technologies,

Products and Policies, https://doi.org/10.1007/978-3-319-66981-6_27 
that mixes of methodologies and modelling frameworks are required to address the various market and system challenges associated to such transition [2].

The available literature on the importance of assessing current and future energy systems and the associated transitions ranges from Life Cycle Assessments (LCA) to energy modelling with economic optimization or policy analyses and recommendations. One focal area has been environmental studies, among which LCA is one of the most established methods. LCA makes it possible to quantify potential impacts to the environment and human health of a product or/and system over the whole life cycle, to identify and discuss areas of improvement, and to conduct fair comparison of selected products or services. Another focal area concentrates on the economic perspective of energy systems, where energy systems optimization models are used to generate future scenarios and evaluate key parameters such as electricity production, related emissions and/or the system costs in the long-term future.

In recent years authors identified the need of combining the best aspects of several modelling frameworks. In particular, the combination of LCA and energy systems optimization models was studied in depth [3-5]. The motivation behind this combination is clear: LCA is a detailed and comprehensive, but static and environment-focused approach whereas modelling of future scenarios of the energy system includes multiple factors such as economic situation without considering environmental issues in detail. As most of the authors point out this combination of methodologies looks very promising, but challenges to its applications remain. Several (case) studies that address different challenges and propose possible solutions are presented and discussed in Sect. 2. The paper closes by providing concluding comments in Sect. 3.

\section{Challenges Identified and Possible Solutions}

A selection of challenges which need to be worked out to realize the full potential of integrating LCA and energy systems optimization models is presented in this section.

\subsection{Prospective Background Data}

Energy conversion technologies are likely to dramatically change in the coming decades not only as a consequence of the energy transition but also as a natural change due to economic, social and technological reasons. Nearly all prospective LCA studies include changes to the energy system when modelling foreground processes. However, in the vast majority of the prospective LCAs the background processes are not modified. The work presented by Cox et al. [6] attempted to use the outputs of the IMAGE model to create future versions of the ecoinvent 
database. According to the authors the use of IMAGE results as a source of future projections greatly simplifies the data collection stage and allows the systematic and consistent modification of ecoinvent background processes and market mixes. The authors pointed out the importance of a standard format of the results to allow to a large degree the automatization of future background databases to reflect different time horizons or scenarios.

\subsection{Lack of Data and Difficulties in the Integration of the Results}

The integration of energy system models and life cycle methods is an approach widely used to facilitate the modelling of prospective scenarios including environmental and economic aspects as well as political constraints, enabling sound decision making and reducing the risk of burden-shifting. Two of the most overwhelming challenges are the lack of data (e.g. power plant operation and emission factors) and the coupling of the results of the energy system models with life cycle inventories. Astudillo et al. [7] identified data gaps related to the energy supply and demand by analysing time-series and literature on emission factors and developed a screening algorithm enabling database integration.

\subsection{Capturing the Interplay of Changes in the Heat Sector and the Electricity Sector in LCM Models}

Bertrand et al. [8] developed a mixed integer linear programming model for the regional valorisation of industrial waste heat from manufacturing, energy production and waste incineration industries. Using waste heat would save resources and reduce emissions, as highlighted by the European Union in 2012 with the Energy Efficiency Directive [9]. By applying their modelling to a case study involving steel plants as heat sources and industries/towns as sinks, they demonstrated the economic profitability of using waste heat for all stakeholders involved.

\subsection{Management and Integration of Stochastic Renewables in LCM Models}

A growing share of renewable intermittent electricity such as wind and solar power leads to a fluctuating feed-in of electricity which might not correspond to electricity demand in a temporal dimension, leading to regional electricity surpluses. Seier et al. [10] proposed "temporal electricity purchase shifting" (TEPS) as one possible 
solution to absorb these electricity surpluses. The authors proposed a wastewater treatment plant (WWTP) as one actor for applying TEPS and demonstrated that TEPS led to decreased electricity purchase from fossil fuel fired power plants and reduced $\mathrm{CO}_{2}$ emissions for the WWTP operator.

\subsection{Integration of Prospective, Economic, Social and Other Issues in LCM Models}

Løkke et al. [11] carried out a socio-technical investigation of the decision process in a policy discussion, through critical review of the tools used and the scenarios developed. This study identified major barriers for the successful application of LCA to major infrastructure projects, provided learnings on designing scenarios and conducting LCA of large infrastructures. The authors demonstrated that a critical design of the LCA can help avoid biased decision-making and proposed LCA-based guidance for projects characterized by a highly political context.

\section{Concluding Comments}

This work has pointed out the importance of the integration of methodologies and modelling for assessing future energy systems. The necessity of using energy system models in combination with different environmental or social assessment tools was highlighted, particularly in prospective assessments. The difficulties in the integration of the results, the lack of data of the emerging energy technologies, the prospective background databases, the relationships between different energy sectors and the stochastic energy production from renewable energies have been highlighted as major challenges. The research work being carried out by the presenters in the session contributed toward finding possible solutions to these challenges and will be crucial to understand and facilitate a smooth energy transition towards a low carbon economy.

\section{References}

1. Baron R, Energy Transition after the Paris Agreement: Policy and Corporate Challenges, OECD, 2016.

2. OECD, Aligning Policies for a Low-carbon Economy, OECD, 2015.

3. Garcia-Gusano D, Garrain D, Dufour J, Prospective life cycle assessment of the Spanish electricity production, Renewable and sustainable Energy Reviews. 75 (2017) 21-34.

4. Röder A, Integration of life-cycle assessment and energy planning models for the evaluation of car powertrains and fuels (Thesis Diss ETH no 14291], Zurich (Switzerland), Swiss Federal Institute of Technology, 2001. 
5. Lund H, Mathiesen B.V, Christensen P, Schmidt J.H, Energy system analysis of marginal electricity supply in consequential LCA,. Int. J. Life Cycle Assess 2010, 15, 260-71.

6. Cox B, Mutel C, Mendoza Beltran A, van Vuuren D. Using integrated assessment model results to develop background databases for prospective LCA, LCM 2017.

7. Astudillo M, Vaillancourt K, Pedinotti-Castelle M, Pineau P.O, Ben Amor M, Using energy system models integrated with life cycle thinking to inform energy transitions in cold regions, LCM 2017.

8. Bertrand A, Mian A, Aggoune R, Maréchal F, Regional waste heat valorisation: a mixed integer linear programming method for energy service companies, LCM 2017.

9. European Parliament and Council, Energy Efficiency Directive 2012/27/EU.

10. Seier $\mathrm{M}$, Schebek $\mathrm{L}, \mathrm{CO}_{2}$ effects of temporal electricity purchase shifting on German wastewater treatment plants, LCM 2017.

11. Løkke S, Pizzol M, Distance to change: LCA as conserving/innovative tool-the case of the green prestigious project "Amager Bakke". LCM 2017.

Open Access This chapter is licensed under the terms of the Creative Commons Attribution 4.0 International License (http://creativecommons.org/licenses/by/4.0/), which permits use, sharing, adaptation, distribution and reproduction in any medium or format, as long as you give appropriate credit to the original author(s) and the source, provide a link to the Creative Commons license and indicate if changes were made.

The images or other third party material in this chapter are included in the chapter's Creative Commons license, unless indicated otherwise in a credit line to the material. If material is not included in the chapter's Creative Commons license and your intended use is not permitted by statutory regulation or exceeds the permitted use, you will need to obtain permission directly from the copyright holder.

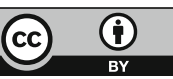

